\title{
BSART (Broadcasting with Selected Acknowledgements and Repeat Transmissions) for Reliable and Low-Cost Broadcasting in the Mobile Ad-Hoc Network
}

\author{
Ingu Han ${ }^{1, *}$, Kee-Wook Rim ${ }^{2}$, and Jung-Hyun Lee ${ }^{1}$ \\ ${ }^{1}$ Dept. of computer science \& information technology, Inha University \\ ${ }^{2}$ Dept. of computer \& information science, Sunmoon University \\ inguhan@gmail.com, rimesunmoon.ac.kr, jhlee@inha.ac.kr
}

\begin{abstract}
In this paper, we suggest enhanced broadcasting method, named 'BSART(Broadcasting with Selected Acknowledgement and Repeat Transmissions)' which reduces broadcast storm and ACK implosion on the mobile ad hoc network with switched beam antenna elements that can enable bidirectional communication. To reduce broadcast storm, we uses DPDP(Directional Partial Dominant Pruning) method, too. To control ACK implosion problem rising on reliable transmission based on ACK, in case of the number of nodes that required message reception is more than throughput, each nodes retransmit messages constant times without ACK which considering message transmission success probability through related antenna elements( $\mathrm{R}$ - method). Otherwise, the number of message reception nodes is less than throughput, each node verify message reception with ACK with these antenna elements(A - method). In this paper, we suggest mixed R - /A - method. This method not only can control the number of message transmitting nodes, can manage the number of ACK for each antenna elements. By simulations, we proved that our method provides higher transmission rate than legacy system, reduces broadcast messages and ACKs.
\end{abstract}

Keywords: selected broadcasting, mobile ad-hoc network, node selection.

\section{Introduction}

Because every node roles not only host but router, the broadcasting method is indispensable to wireless ad - hoc network for searching special node's positioning information or indentifying existence of any node. To control broadcast storm problem which too heavily duplicated messages are occurred when nodes operate broadcasting, it is useful a method that only a few node receives forwarded message[1][2][3]. The CDS(connected dominant set) can be is equal to forward node set for those network

\footnotetext{
* "This research was supported by the MKE(Ministry of Knowledge Economy), Korea, under the ITRC(Information Technology Research Center) Support program supervised by the IITA(Institute of Information Technology Advancement)" (IITA-2009-C1090-0902-0020.
} 
set, but it is proved that finding the lowest cost CDS is NP - complete problem. There are various heuristic methods to search CDS, the one method is source - dependent broadcasting which consists of only one CDS per whole network, another method is source - independent broadcasting which consists of one CDS per each network, the other method which mixes source-independent method and source-dependent method[2][3][5][6]. In general, the former method can reduce the number of selected nodes, the latter method can support node's mobility and it also can split up whole traffics.

The wireless ad - hoc network environment may increase the rate of error during transmission rather than wired network environment, and the probability of message loss is high because the signals interfere and collide with each other. The one solution of these problems is ACK transmission and the other solution is selective flooding which can receive partially overlapped messages [4][7][8]. But if all nodes that received broadcasting message response with ACK message, it may cause ACK implosion which many ACK messages occur simultaneously and it leads congestion[9]. Furthermore it can reduce the performance of link in the case of ACK message is missed, because nodes must retransmit messages[1][9].

Related researches show that the node which required receiving and forwarding is applied ACK response method, and dead - end node that required only receiving can receive duplicated message from neighboring nodes in the wireless ad - hoc network environment with omnidirectional antennas[2][11]. But these methods select forwarding nodes that neighboring all dead - end nodes with definite number of forwarding nodes compulsory, it may increase the number of forwarding node. This means that the number of broadcasting messages and ACK messages are increased, and so it can't be appropriate solution for broadcast storm or ACK implosion.

The methods that reducing duplicated messages in the wireless ad - hoc network with directional antenna are message forwarding in the MAC layer, directional self pruning, three - hop horizon pruning and etc. But these research didn't consider reliable transmission or ACK implosion problem though they attempt to reduce broadcasting messages[5][8][12]. Most research considered just one of them, but Lou-Wu considered both problems[1][2][3][6][10][11][14][15].

In this paper, we suggest a low-cost, reliable broadcasting method with switched beam antenna which enables directional transmission on mobile ad-hoc network. Our method manages broadcasting storm with DPDP and in case of ACK implosion, we applies SART selectively. By simulation, we proved our method quite reduced both of broadcast storm and ACK implosion and enables reliable transmission with directional antenna on mobile ad-hoc network.

This instruction file for Word users (there is a separate instruction file for LaTeX users) may be used as a template. Kindly send the final and checked Word and PDF files of your paper to the Contact Volume Editor. This is usually one of the organizers of the conference. You should make sure that the Word and the PDF files are identical and correct and that only one version of your paper is sent. It is not possible to update files at a later stage. Please note that we do not need the printed paper.

We would like to draw your attention to the fact that it is not possible to modify a paper in any way, once it has been published. This applies to both the printed book and 
the online version of the publication. Every detail, including the order of the names of the authors, should be checked before the paper is sent to the Volume Editors.

\section{System Model}

The Mobile ad-hoc network that discussed in this paper is divided by not overlapped $\mathrm{K}$ sectors and we supposed that each sector contains switched beam antennas which controls each sector.

Let $G_{o}$ where the transmission gain using omni-directional antenna, $G_{d}$ where the transmission gain using directional antenna, in general the following inequality comes, $\mathrm{G}_{\mathrm{d}}>\mathrm{G}_{\mathrm{o}}$. In case that omni-directional antenna using $10 \mathrm{dBm}$ power reaches $250 \mathrm{~m}$, but using the same antenna which beam angle setted by $60^{\circ}$, it reaches $450 \mathrm{~m}[16]$. A switched beam antenna that using only one antenna element at a time, omni-directional broadcasting can be realized by sequential sweeping process[16]. In other words, a clockwise antenna element $0,1,2, \ldots, \mathrm{K}-1$ transmits messages with constant delay. If it transmits only special antenna elements group, it can realize selective flooding, too. Let $d_{d}=\lambda d_{o}$ (where $\lambda>1, d_{d}$ : reaching distance using directional antenna, $d_{o}$ : reaching distance using omni-directional antenna), the reaching area using directional antenna is larger than area using omni-directional antenna for $\lambda^{2}$ times, so we can regard network model that increasing $\lambda^{2}$ times node per neighbor node.

The mobile ad-hoc network can be described by unit disk graph $\mathrm{G}=(\mathrm{V}, \mathrm{E})$ where $\mathrm{V}$ is set of wireless mobile nodes and $E$ is set of node's edge. A edge $(u, v) \in E$ means wireless link between node $\mathrm{u}$ and node $\mathrm{v}$ which can reach each other. We suppose that all wireless links $(\mathrm{u}, \mathrm{v})$ satisfy symmetrical property. In other words, if u can transmit messages to $\mathrm{v}, \mathrm{v}$ can transmit to $\mathrm{u}$, too. We supposed $\mathrm{u}$ 's neighbor nodes to $\mathrm{u}$ can reach and declare u's neighbor nodes set to $\mathrm{N}(\mathrm{u})$. By definition, $\mathrm{u} \in \mathrm{N}(\mathrm{u})$.

If we declare u's 2-hop neighbor nodes set to $\mathrm{N}(\mathrm{N}(\mathrm{u}))$ or $\mathrm{N}_{2}(\mathrm{u})$, a inequality $\{\mathrm{u}\} \subseteq$ $\mathrm{N}(\mathrm{u}) \subseteq \mathrm{N}_{2}(\mathrm{u})$ is established and $\mathrm{N}(\mathrm{v}) \subseteq \mathrm{N}_{2}(\mathrm{u})$ follows if $\mathrm{v} \in \mathrm{N}(\mathrm{u})$. If we declare $\mathrm{N}_{\mathrm{h}}(\mathrm{u})$ that within h-hop nodes from $\mathrm{u}$ and $\mathrm{H}_{\mathrm{h}}(\mathrm{u})$ that h-hop nodes from $\mathrm{u}$, a following equation comes, $\mathrm{N}_{\mathrm{h}}(\mathrm{u})=\mathrm{N}_{\mathrm{h}-1}(\mathrm{u}) \cup \mathrm{H}_{\mathrm{h}}(\mathrm{u})$ where $\mathrm{h} \geq 1$ and $\mathrm{N}_{0}(\mathrm{u})=\mathrm{H}_{0}(\mathrm{u})=\{\mathrm{u}\}$. For the convenience, we omit subscript if $h=1$.

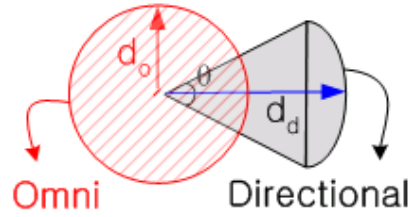

$$
d_{d}=\lambda d_{0}(\lambda>1)
$$

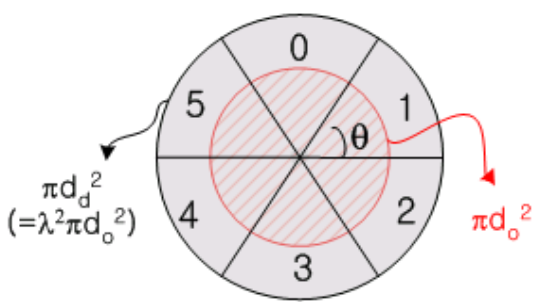

Fig. 1. Omnidirectional antenna and directional antenna, directional antenna which consist of 6 antenna elements $(\mathrm{K}=6)$ 


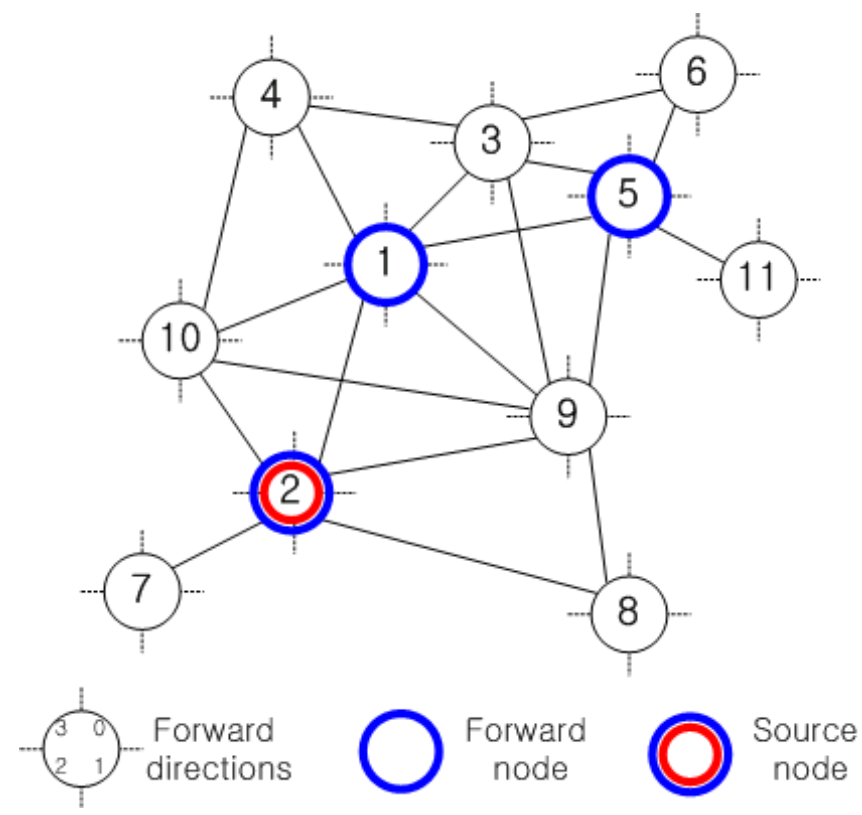

Fig. 2. An example using 4 antenna elements

Fig. 2 describes $\mathrm{N}_{2}(1)=\mathrm{N}(1) \cup \mathrm{H}_{2}(1)=\{1,2,3,4,5,9,10\} \cup\{6,7,8,11\}=$ $\{1,2,3,4,5,6,7,8,9,10\}$.

Nodes can communicate directly with antenna element $i$, where the nodes which using unoverlaped $\mathrm{K}$ antenna elements, so to speak 1-hop away nodes set declared to $\mathrm{N}_{\mathrm{i} \rightarrow}(\mathrm{u})$. Then $\mathrm{N}_{\mathrm{i} \rightarrow}(\mathrm{u}) \subseteq \mathrm{N}(\mathrm{u})$ and $\mathrm{N}(\mathrm{u})=\mathrm{N}_{0 \rightarrow}(\mathrm{u}) \cup \mathrm{N}_{2 \rightarrow}(\mathrm{u}) \cup \ldots \cup \mathrm{N}_{\mathrm{K}-1 \rightarrow}(\mathrm{u}) \cup\{\mathrm{u}\}$.

A degree of node $\mathrm{u}$ is $|\mathrm{N}(\mathrm{u})|-1=\left|\mathrm{N}_{0 \rightarrow}(\mathrm{u})\right|+\left|\mathrm{N}_{2 \rightarrow}(\mathrm{u})\right|+\ldots+\left|\mathrm{N}_{\mathrm{K}-1 \rightarrow}(\mathrm{u})\right|$ where $\left|\mathrm{N}_{\mathrm{i} \rightarrow}(\mathrm{u})\right|$ is the number of nodes that belongs to $\mathrm{N}_{\mathrm{i} \rightarrow}(\mathrm{u})$. We suppose that antenna element's direction for every node maintains fixed direction by using magnetic compass or etc..

Because radiowave travels straight, there are diagonal relationship established between antenna elements for $\mathrm{u}$ and $\mathrm{v}($ where $\mathrm{u} \in \mathrm{N}(\mathrm{v}))$ communicate each other. In other words, the antenna $\mathrm{j}$ where $0 \leq \mathrm{j} \leq \mathrm{K}-1$ which transmit messages $\mathrm{u}$ to $\mathrm{v}$, the antenna that $\mathrm{v}$ uses must $(\mathrm{j}+(\mathrm{K} / 2)) \bmod \mathrm{K}$.

In fig. 2 , the antenna is 1 when node 2 transmit messages to node 8 , so node 8 can receive message from node 2 via antenna 3 . If $D_{v \rightarrow u}=\{i l u \in N i \rightarrow(v)\}, D_{v \rightarrow v}=U_{w} \in v$ $D_{v \rightarrow w}$ where $V$ is nodes set that satisfy $V \subseteq N(v)$. For example, $D_{8 \rightarrow 2}=\{3\}, N(10)=$ $\{1,2,4,9\}, D_{10 \rightarrow \mathrm{N}(10)}=\mathrm{D}_{10 \rightarrow 1} \cup \mathrm{D}_{10 \rightarrow 2} \cup \mathrm{D}_{10 \rightarrow 4} \cup \mathrm{D}_{10 \rightarrow 9}=\{0\} \cup\{1\} \cup\{0\} \cup\{1\}=$ $\{0,1\}$ in fig. 2 .

In this paper, we suppose that node $\mathrm{u}$ broadcast HELLO periodically for obtain neighbor node's state information. In other words, node $v$ that receives HELLO from $u$, transmits HELLO to $\mathrm{u}$ via piggybacking to communicate with 1-hop neighbor node $\mathrm{N}(\mathrm{v})$. 


\section{BSART: Broadcasting with Selected Acknowledgement and Repeat Transmissions}

Suppose that node $v$ gets self forwarding node set $F(v)$ and dead-end set $D(v)$ using DPDP. Then $v$ gets nodes set $T_{i}$ to transmit message that not classified $F(v)$ and $D(v)$ per antenna element $0,1, \ldots, \mathrm{K}-1$, where $\mathrm{T}_{\mathrm{i}}=\mathrm{N}_{\mathrm{i} \rightarrow}(\mathrm{v}) \cap\{\mathrm{F}(\mathrm{v}) \cup \mathrm{D}(\mathrm{v})\}$, i means antenna element's ID, and $0 \leqslant \mathrm{i} \leqslant \mathrm{K}-1$.

Then $v$ gets nodes set $T_{i}$ to transmit message that not classified $F(v)$ and $D(v)$ per antenna element $0,1, \ldots, \mathrm{K}-1$, where $\mathrm{T}_{\mathrm{i}}=\mathrm{N}_{\mathrm{i} \rightarrow}(\mathrm{v}) \cap\{\mathrm{F}(\mathrm{v}) \cup \mathrm{D}(\mathrm{v})\}$, i means antenna element's ID, and $0 \leqslant \mathrm{i} \leqslant \mathrm{K}-1$. In case that $\mid \mathrm{T}_{\mathrm{i}} \mathrm{l}$ exceeds a constant number then nodes transmit messages repeatedly constant times(for convenience, we call this A-method), otherwise nodes identify message reception via ACK(for convenience, we call this Rmethod). For example, to prohibit receiving 3 messages per antenna simultaneously, set $\mathrm{c}=3$.

It can increase conjestion by ACK and messages generated simultaneously, if ACK identification(A-method) just as Low-Wu and method that get oppotunity from neighbor nodes minimum 2 times are applied at the same time for the area that mixed $\mathrm{F}(\mathrm{v})$ and $\mathrm{D}(\mathrm{v})$, via each antenna element $\mathrm{i}$ because a network with directional antenna, each antenna can control separately[10]. And if one node receives ACK heavily, the ACK implosion occurs and this situation cause not only performance decrease, extreme delay.

Let the $\mathrm{M}(\mathrm{v}$, s, seq\#, $\mathrm{F}(\mathrm{v})$, mode, DATA) is message to broadcast where $\mathrm{v}$ is ID of forwarding node, $s$ is broadcast message source node's ID, seq\# means sequential number of broadcast message that generated by s. s and seq\# are used for identifying overlaped or not. Data means transmission message. $F(v)$ is forward node set that acquired by DPDP. Besides, all $\mathrm{v}$ must get $\mathrm{R}_{\mathrm{v}}$ which antenna elements set that to apply A-method and $A_{v}$ which antenna elements set that to apply R-method. Then for every antenna element $\mathrm{i}$ where $\mathrm{i} \in\{0,1, \ldots, \mathrm{K}-1\}$, v calculates $\mathrm{T}_{\mathrm{i}}=\mathrm{N}_{\mathrm{i}} \rightarrow(\mathrm{v}) \cap\{\mathrm{F}(\mathrm{v}) \cup \mathrm{D}(\mathrm{v})\}$. If $\left|T_{j}\right|<c$, generate $A_{v}$ to apply A-method. If $\left|T_{j}\right| \geqslant c, v$ generates $R_{v}$ to apply R-method. And then transmits $M$ with each antennas. Specially, transmission via $R_{v}$ antenna element, it retransmits $1 / \mathrm{p}$ times periodically where $\mathrm{p}$ is transmission success probability via antenna element i. Finally, mode in the message $M$ sets to A when A-method is applied or sets to $\mathrm{R}$ when R-method is applied.

- $\quad \mathrm{D}(\mathrm{v})$ : dead-end node set for $\mathrm{v}$

- $\mathrm{F}(\mathrm{v})$ : forward node set for $\mathrm{v}$

- $\quad \mathrm{N}_{\mathrm{i} \rightarrow}(\mathrm{v})$ : neighbor node set which $\mathrm{v}$ can transmit message with antenna element $\mathrm{i}$

- $\mathrm{TX}_{\mathrm{max}}$ : throughput of retransmission

- WAIT $_{\max }$ : waiting time to receive ACK

- $\mathrm{T}_{\text {int }}$ : time slot for transmission $\mathrm{M}$

- $\quad$ tx_cnt $_{\mathrm{i}}$ : the number of transmission times via antenna element $\mathrm{i}$

- timer $^{\mathrm{i}}{ }_{\text {wait }}$ : timer that waiting ACK after transmits $\mathrm{M}$ via antenna element $\mathrm{i}$

- $\mathrm{A}_{\mathrm{v}}$ : antenna element set for $\mathrm{v}$ to apply A-method

- $\mathrm{R}_{\mathrm{v}}$ : antenna element set for $\mathrm{v}$ to apply R-method

- $\quad \mathrm{P}_{\mathrm{v}}^{\mathrm{i}}$ : nodes set that response with $\mathrm{ACK}$ when receives $\mathrm{M}$ via antenna element $\mathrm{i}$ where $\mathrm{i} \in \mathrm{A}_{\mathrm{v}}$ where $\mathrm{P}_{\mathrm{v}}^{\mathrm{i}}=\mathrm{N}_{\mathrm{i} \rightarrow}(\mathrm{v}) \cap\{\mathrm{F}(\mathrm{v}) \cup \mathrm{D}(\mathrm{v})\}$. If, $\mathrm{i} \in \mathrm{R}_{\mathrm{v}}, \mathrm{P}_{\mathrm{v}}^{\mathrm{i}}=\Phi$. 
- $\quad$ ack_req : in case of waiting ACK from neighbor node $\mathrm{u}$ where $\mid \mathrm{P}_{\mathrm{v}}^{\mathrm{i}} \mathrm{K} \mathrm{c}$ and $\mathrm{u}$ $\in \mathrm{P}_{\mathrm{v}}^{\mathrm{i}}$ set to 1 , otherwise set to 0 where $\mathrm{P}_{\mathrm{v}}^{\mathrm{i}}=\mathrm{N}_{\mathrm{i} \rightarrow}(\mathrm{v}) \cap\{\mathrm{F}(\mathrm{v}) \cup \mathrm{D}(\mathrm{v})\}$.

- $\quad \operatorname{acked}_{\mathrm{u}}$ : set 1 when receives $\mathrm{ACK}$ from ack_req $\mathrm{u}_{\mathrm{u}}=1$, otherwise 0

- $\quad \operatorname{ACK}(w, v, s$, sqn\#): ACK for M(v, s, seq\#, F(v), mode, DATA)

Algorithm: BSART(Broadcasting with Selected Acknowledgements and Repeat Transmissions)

input: $M\left(u, s\right.$, seq\#, $F(u), P_{u}$, mode, DATA), C

output: $A_{v}, R_{v}, F(v), M(v, s$, seq\#, $F(v)$, mode, DATA)

initial state: $\mathrm{tx}_{-} \mathrm{cnt}_{\mathrm{i}}=0 ; \mathrm{A}_{\mathrm{v}}=\mathrm{R}_{\mathrm{v}}=\Phi$; for all $\mathrm{i} \in\{0,1, \ldots, \mathrm{K}-$

1), $\mathrm{P}_{\mathrm{v}}^{\mathrm{i}}=\Phi$

// supposed that ACK can not be lossed

case 1: nove $v$ is a broadcast source

$1.1 \mathrm{~V}=\mathrm{s} ; \mathrm{seq} \#=\mathrm{seq} \#+1$

$1.2 \mathrm{~B}(\mathrm{u}, \mathrm{v})=\mathrm{N}(\mathrm{v}) ; \mathrm{U}(\mathrm{u}, \mathrm{v})=\mathrm{H}_{2}(\mathrm{v}) / / \mathrm{u}=\Phi$

1.3 jump to 2.4

case 2: in case that receive $\mathrm{M}(u, \mathrm{~s}$, seq\#, $F(u)$, mode, DATA) from neighbor node $u$

2.1 if mode=A, $\mathrm{V} \in \mathrm{F}(\mathrm{u})$, execute followings, otherwise jump to 2.2 // ACK transmission

2.1 .1 if $\mathrm{M}$ is overlapped, stop.

2.1.2 transmit $A C K(v, u, s$, seq\#) via antenna element $\mathrm{f}$ which received $\mathrm{M}$, jump to 2.3

2.2 if $M$ is not overlapped, receive $M$ and stop // dead-end node

$2.3 \mathrm{~B}(\mathrm{u}, \mathrm{v})=\mathrm{N}(\mathrm{v})-\mathrm{N}(\mathrm{u}) ; \mathrm{U}(\mathrm{u}, \mathrm{v})=\mathrm{H}_{2}(\mathrm{v})-\mathrm{N}(\mathrm{u})-\mathrm{N}(\mathrm{N}(\mathrm{v}) \cap$ $\mathrm{N}(\mathrm{u}))$

2.4 calculate $\mathrm{F}(\mathrm{v})$ with $\mathrm{DPDP}$

2.5 for each antenna element $i(i=0$ to $\mathrm{K}-1)$, calculate $\mathrm{P}_{\mathrm{v}}^{\mathrm{i}}=\mathrm{N}_{\mathrm{i}} \rightarrow(\mathrm{V}) \cap\{\mathrm{F}(\mathrm{v}) \cup \mathrm{D}(\mathrm{v})\}$ then execute followings

2.5.1 $i$ where $\left|\mathrm{P}_{\mathrm{v}}^{\mathrm{i}}\right| \mathrm{Z}_{\mathrm{C}}$ execute followings, or jump to 2.5.2 // R-method

$2.5 .1 .1 \mathrm{R}_{\mathrm{v}}=\mathrm{R}_{\mathrm{v}} \cup\{\mathrm{i}\}$.

2.5.1.2 for all $\mathrm{x}$ where $\mathrm{x} \in \mathrm{P}_{\mathrm{v}}^{\mathrm{i}}$, ack_req $\mathrm{x}_{\mathrm{x}}=0$

2.5.1.3 mode=R; $\mathrm{P}_{\mathrm{v}}=\boldsymbol{\Phi}$. // retransmission mode

2.5 .2 if $\left|\mathrm{P}_{\mathrm{v}}^{\mathrm{i}}\right|<\mathrm{C} / / \mathrm{A}$-method

2.5.2.1 $A_{v}=A_{v} \cup\{i\}$.

2.5.2.2 mode $=A$. / / ACK waiting mode

2.5.2.3 for all $\mathrm{w}$ where $\mathrm{w} \in \mathrm{P}_{\mathrm{v}}^{\mathrm{i}}, \mathrm{ack}_{\mathrm{r}} \mathrm{req}_{\mathrm{w}}=1 . / /$ set $\mathrm{ACK}$ request

2.6 each antenna element $i$ execute followings by sequential sweeping

2.6.1 if $i \in R_{v}$, transmit $M(v, s$, seq\#, $F(v)$, mode, DATA) via antenna element i $1 / \mathrm{p}$ times retransmit every tint time slot

2.6 .2 if $i \in A_{v}$, execute followings via antenna element $i$ 


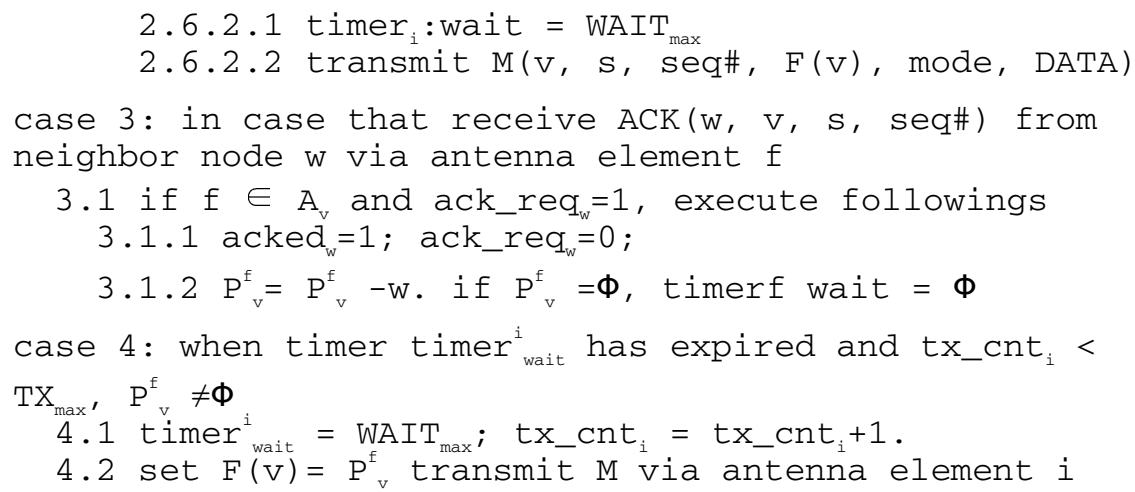

In case that broadcast source node is 0 , we will apply BSART. In this case, we suppose that $c=2$, so when only one forward node per antenna element, nodes response with ACK and suppose that if node $\mathrm{v}$ transmit $\mathrm{M}$ with only one directional antenna element, put the transmission success probability p set to $1 / 2$. By algorithm 2.3 and 2.4, we will get $\mathrm{B}(\Phi, 0)=\mathrm{N}(0)-\mathrm{N}(\Phi)=\mathrm{N}(0)=\{0,1,2,3,4,6,8\}, \mathrm{U}(\Phi, 0)=\mathrm{H}_{2}(0)-\mathrm{N}(\Phi)$ - $\mathrm{N}(\mathrm{N}(\Phi) \cap \mathrm{N}(0))=\mathrm{H}_{2}(0)=\{5,7,9\}, \mathrm{F}(0)=\{2,4,8\}(\mathrm{F}(0)=\{3,6,8\}$, too). By algorithm 2.5 and 2.6 we will get $\mathrm{R} 0=\{0,1\}, \mathrm{A}_{0}=\{2,3\}, \mathrm{P}_{20}=\{4\}, \mathrm{P}_{30}=\{6\}$. Because the transmission success probability $\mathrm{p}=1 / 2, \mathrm{M}$ will be transmitted 2 times with antenna 0,1 . By 2.5.2, node 2, 3 included $\mathrm{A}_{0}$ will wait $\mathrm{ACK}$. That is to say ack_req $\mathbf{q}_{4}=1$, ack_req $_{6}=1$. Same way node $0,4,8$ which included $F(0)=\{2,4,8\}, F(2)=\Phi, A_{2}=\{0\}$, $\mathrm{R}_{2}=\Phi, \mathrm{P}_{2}^{0}=\{7\} \mathrm{F}(4)=\Phi, \mathrm{A}_{4}=\{3\}, \mathrm{R}_{4}=\Phi, \mathrm{P}_{4}^{3}=\{5\}, \mathrm{F}(8)=\Phi, \mathrm{A}_{8}=\{1\}, \mathrm{R}_{8}=\Phi, \mathrm{P}_{8}^{1}=\{9\}$.

If supposed that ACK can not be lossed, consider messages that generated by BSART algorithm in case $\mathrm{c}=2$. A message transmission that required ACK occurs 5 times with A-method, so ACK occurs 5 times. In case that applied R-method, messages are transmitted by antenna element 0,1 , broadcasting is accomplished 2 times per each antenna element regardless the number of receiver nodes. In other words, number of message which twice retransmission, so total number of occured message is $14(=5+5+2 \times 2)$. Because receive nodes can receive with 4 antennas, node 0 generates 4 messages. In the same way, node 2 generates 2 messages, node 3, 4, 5, 8 generates 1 message each other. If transmission successes without ACK implosion, ACK occurs from forward node set $\{1,2,3,4,5,8,9\}$ for each except source node 0 . Therefore 7 messages are generated and this is more than BSART. Moreover it is the minimum number that can be generated besides at the node 0 can occur ACK implosion if it receives 2 ACK with antenna 0,1 .

\section{Experiments and Evaluation}

We considered $1000 \times 1000$ array with $20,40,60,80,100$ nodes and nodes distributed by random number generator. Table 1 shows major parameters. Compared protocols are $\mathrm{BF}$ (blind flooding), $\mathrm{HHH}, \mathrm{SHJ}$, and etc. [8] [16]. The BF generates many overapped messages but the message transmission ratio is high. 
The speed of node is set to $0-20 \mathrm{~m} / \mathrm{s}$ and we supposed random-way point. Considered $\mathrm{HHH}$, each forward node set one forwarding node per each direction. A designated node transmits message to all direction except received direction when message received. In the SHJ algorithm, each node $\mathrm{u}$ forwards broadcast message with neighbor node information $\mathrm{N}(\mathrm{u})$, and $\mathrm{v}$ which receives that message f direction which satisfies $\mathrm{N}_{\mathrm{f}}(\mathrm{v})-\mathrm{N}(\mathrm{u})$ $\{\mathrm{u}\} \neq \Phi$. The simulation items as follows.

$\square$ forwarding direction (antenna element) ratio

$\square$ message forwarding ratio by number of nodes and antenna elements and movement speed

$\square$ ACK message processing time as number of antenna elements

Table 1. Major parameters for simulation

\begin{tabular}{ll}
\hline Parameter & Value \\
\hline TXmax & 4 \\
K & $4,6,8$ \\
WAITmax & 10 \\
$\mathrm{c}$ & $2,3,4,5$ \\
$\mathrm{p}$ & 0.3 \\
\hline
\end{tabular}

The experiments carried with NS-2 simulator and we programmed each module with $\mathrm{C}++$ and $\mathrm{Tcl} / \mathrm{Tk}$.

Fig. 3 shows selected antenna elements ratio which in order to broadcast in case that put the number of nodes to $20,40,60,80,100$. In the case of BSART, less than $30 \%$ antenna elements are used, that is, $1.2(=4 \times 0.3)$ per nodes and it is very similiar to $\mathrm{HHH}$ algorithm. In the case of BF algorithm, as number of nodes increase, messages are transmitted to all direction. SHJ case, it uses 2.4 the maximum.

Fig. 4, 5, 6 shows message transmission ratio as number of nodes, antenna element and movement speed respectively. As number of nodes increases, the transmission

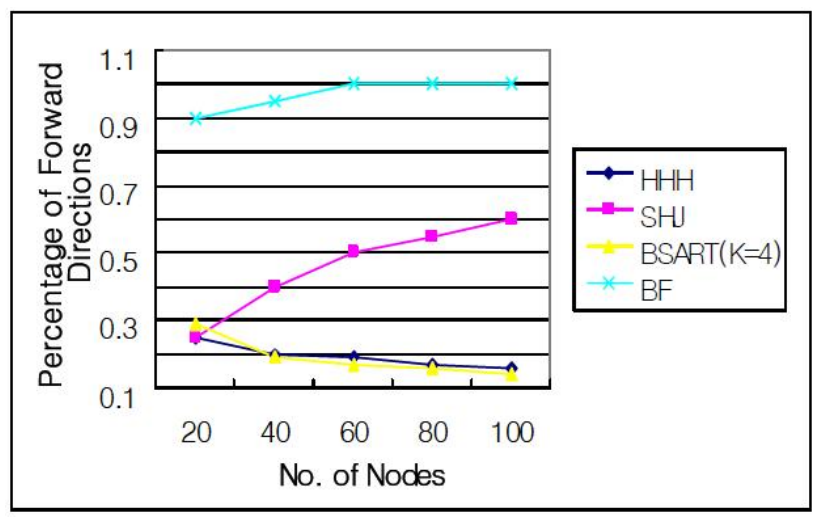

Fig. 3. Antenna element ratio per node 


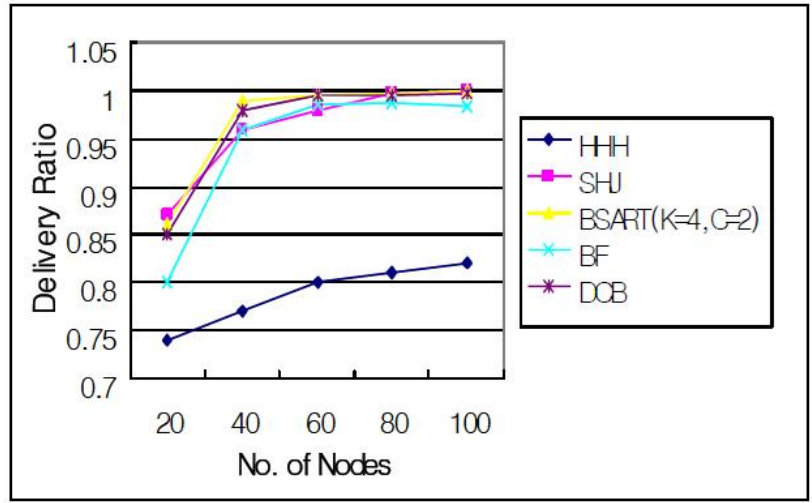

Fig. 4. Message delivery ratio per nodes

ratio increases and $\mathrm{HHH}$ shows the lowest transmission ratio. Except $\mathrm{BF}$, the transmission ratio is similar to each other and BSART and DCB show almost $100 \%$ in case that number of nodes is over 60.

Fig. 5 also shows transmission ratio when $\mathrm{c}=2,3,4,5$ to apply A-method for antenna element 1, 4, 8. In general, as c increases, A-method is used frequently and it leads message transmission with ACK. As c increases, message transmission ratio is increases consequently just as Fig. 5.

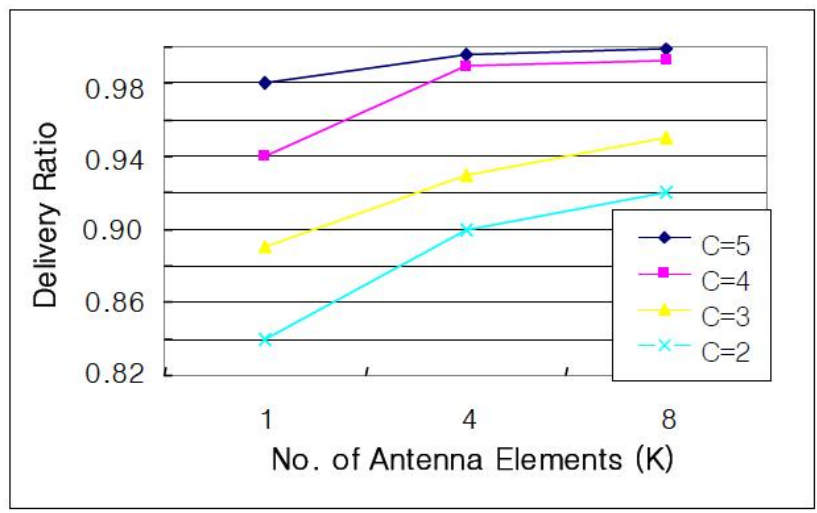

Fig. 5. Message delivery ratio per antenna element

Fig. 6 shows transmission ratio as node's movement when number of nodes is 60 . $\mathrm{BF}$ and SHJ show high ratio regardless node's movement, DCB-SD and BSART show over $90 \%$ transmission ratio. HHH shows the hightest ratio as node's movement[11]. 


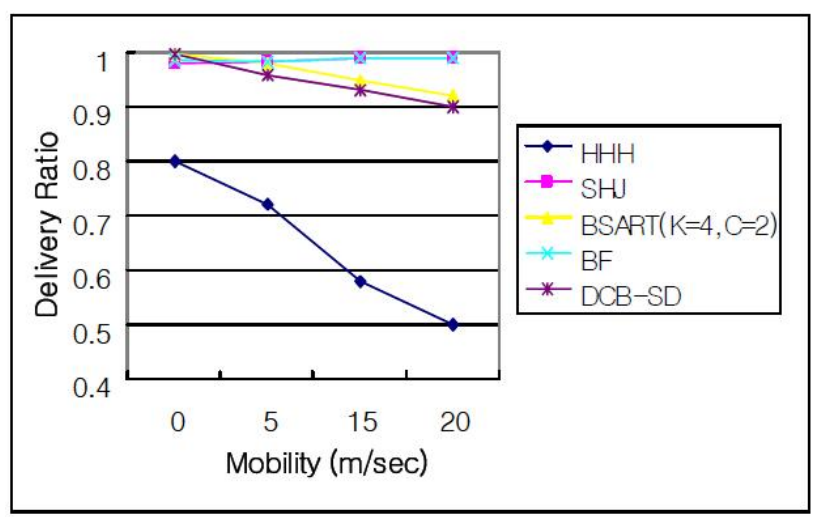

Fig. 6. Message delivery ratio per mobility

Fig. 7 shows ACK processing time as c constant which decides A-method. As c is smaller and $\mathrm{K}$ is bigger, the processing time gets short. As $\mathrm{K}$ increases, the number of nodes to transmit messages per antenna element decreases and it leads c to smaller.

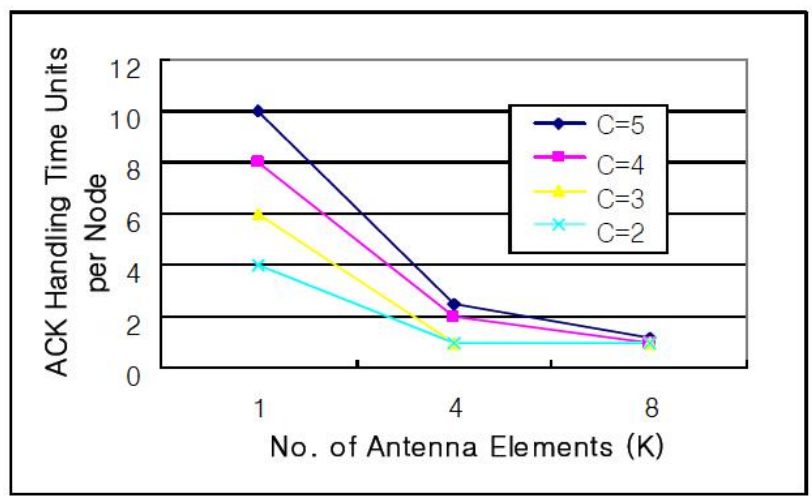

Fig. 7. ACK handling time per No. of antenna element

\section{Conclusion}

In this paper, we proposed BSART(Broadcasting with Selective Acknowledgements and Repeat Transmission) that provides bidirectional, low cost and reliable broadcast with switched beam antenna in the mobile ad-hoc network. We considered A-method based ACK per antenna element and R-method which only retransmission messages constant times without ACK to deal with ACK implosion that appears reliable transmission, that is, antenna elements which number of receive nodes over $\mathrm{c}$, let the node retransmit message constant times, otherwise require ACK. By experiments, we proved our algorithm reduces number of broadcast message and ACK, supports reliable message transmission. The condition which under $20 \mathrm{~m} / \mathrm{s}$ movement speed, $\mathrm{K}=4$ and $\mathrm{c}=2$, 
we proved over $90 \%$ message transmission ratio by experiments. And close performance analysis of BSART and appliable BSART to sensor network are expected.

\section{References}

1. Ni, S., Tseng, Y., Chen, Y., Sheu, J.: The broadcast storm problem in a mobile ad hoc network. In: Proc. MOBICOM 1999, pp. 151-162 (1999)

2. Lim, H., Kim, C.: Flooding in wireless ad hoc networks. Computer Communications 24(34), 353-363 (2001)

3. Lou, W., Wu, J.: On reducing broadcast redundancy in ad hoc wireless networks. IEEE Trans. Mobile Computing 1(2), 111-122 (2002)

4. Basagni, C.S., Conti, M., Giordano, S., Stojmenovic, I. (eds.): Mobile Ad Hoc Networking. IEEE/Wiley (2004)

5. Dai, F., Wu, J.: Efficient broadcasting in ad hoc networks using directional antennas. IEEE Trans. Parallel \& Distributed Systems 17(4), 1-13 (2006)

6. Wu, J., Dai, F.: A generic distributed broadcast scheme in ad hoc wireless networks. IEEE Trans. Computers 53(10), 1343-1354 (2004)

7. Boukerche, A., Chlamta, I. (eds.): Handbook of Algorithms for Mobile and Wireless Networking and Computing. CRC Press, Boca Raton (2005)

8. Hu, C., Hong, Y., Hou, J.: On mitigating the broadcast storm problem with directional antennas. In: Proc. IEEE ICC 2003 (2003)

9. Impett, M., Corson, M.S., Park, V.: A receiver-oriented approach to reliable broadcast ad hoc networks. In: Proc. WCNC 2000, pp. 117-122 (2000)

10. Low, W., Wu, J.: A reliable broadcast algorithm with selected acknowledgements in mobile ad hoc networks. In: Proc. IEEE GLOBECOM 2003 (2003)

11. Low, W., Wu, J.: Double-covered broadcast(DCB): a simple reliable broadcast algorithm in MANETS. In: Proc. IEEE INFOCOM 2003 (2003)

12. Spohn, M., Garcia-Luna-Aceves, J.J.: Improving route discovery in on-demand routing protocols using two-hop connected dominating sets. Ad Hoc Networks 4(4) (July 2006)

13. Lou, W., Wu, J.: Localized broadcasting in mobile ad hoc networks using neighbor designation, Technical Report, Dep't of Computer Science and Engineering, Florida Atlantic University, Boca Raton, FL (July 2003)

14. Qayyum, A., Viennot, L., Laouiti, A.: Multipoint relaying for flooding broadcast message in mobile wireless networks. In: Proc. 35th Hawaii Int'l Conf. System sciences (HICSS35), January 2002, pp. 3898-3907 (2002)

15. Alagar, S., Venkatesan, S., Cleveland, J.: Reliable broadcast in mobile wireless networks. In: Proc. MILCOM 1995, pp. 236-240 (1995)

16. Choudhury, R.R., Vaidya, N.H.: Performance of ad hoc routing using directional antennas. Ad Hoc Networks 3(2), 157-173 (2005)

17. Shen, C.C., Huang, Z., Jaikaeo, C.: Directional broadcast for ad hoc networks with percolation theory, Tech. Report, Comp. and Info. Sciences, Univ. of Delaware (February 2004) 